\title{
SENYAWA DAMARA-20,24-DIEN-3-ON YANG BERAKTIVITAS SITOTOKSIK TERHADAP SEL MCF-7 DARI KULIT BATANG CHISOCHETON MACROPHYLLUS (MELIACEAE)
}

\author{
Nurlelasari, Nurabi Ferdiana, Subekti Mauluddian, Desi Harneti \\ Moelyono Moekti, Wardoyo, Rizki Abdullah, Unang Supratman, dan Khalijah Awang \\ Institut Teknologi Bandung \\ email korespondensi: u_supratman@unpad.ac.id
}

\begin{abstract}
Abstrak
Senyawa triterpenoid damaran, damara-20,24-dien-3-on (1) telah diisolasi dari kulit batang Chisocheton macrophyllus (Meliaceae). Struktur kimia kedua senyawa tersebut telah ditetapkan berdasarkan data spektroskopi dan perbandingan data spektra yang diperoleh dari literatur. Senyawa damara-20,24-dien-3-on menunjukkan aktivitas sitotoksik terhadap sel kanker payudara manusia MCF-7 dengan nilai IC50 $28 \mathrm{mM}$.
\end{abstract}

Kata kunci: Aktivitas sitotoksik, sel MCF-7, triterpenoid damaran, Chisocheton macrophyllus, Meliaceae.

\begin{abstract}
Dammarane triterpenoid, dammara-20,24-dien-3-one (1) has been isolated from the bark of Chisocheton macrophyllus (Meliaceae). Chemical structure of compound was determined on the basis of spectroscopic data and comparison with those spectra data previously reported. Compound dammara-20,24-dien-3-one exhibited cytotoxic activity against MCF-7 human breast cancer cell lines with IC50 values of $28 \mathrm{mM}$, respectively.
\end{abstract}

Key words: Cytotoxic activity, MCF-7 cell, dammarane triterpenoid, Chisocheton macrophyllus, Meliaceae.

\section{PENDAHULUAN}

Genus Chisocheton, salah satu anggota famili Meliaceae terdiri dari 50 spesies yang terdistribusi merata di India, Thailand, Malaysia dan Indonesia. Genus Chisocheton adalah tumbuhan subtropis dan tropis yang telah dikenal mengandung senyawa limonoid yang beraktivitas insektisidal. Studi fitokimia sebelumnya pada spesies Chisocheton telah dilaporkan adanya beberapa senyawa yang menarik meliputi limonoid, senyawa tipe-meliasin yang beraktivitas antijamur, triterpenoid damaran, dan alkaloid spermidin. Dalam penelitian berkelanjutan kami dalam pencarian senyawa antikanker dari tumbuhan Meliaceae Indonesia, ekstrak metanol Chisocheton macrophyllus menunjukkan aktivitas sitotoksik terhadap sel kanker payudara manusia MCF-7 dengan nilai IC50 40,5mM.

C. macrophyllus, adalah tumbuhan tinggi dan ditemukan tumbuh di hutan hujan tropis di bagian utara pulau Sulawesi, Indonesia. Tanaman ini dikenal dengan nama ma-aa di Sulawesi dan minyak dari bijinya digunakan untuk penerangan. Penelitian sebelumnya, telah melaporkan bahwa daun C. macrophyllus mengandung triterpenoid damaran yang beraktivitas antitumor, tetapi kulit batang dari tanaman ini belum dilaporkan kandungan kimianya. Pada paper ini, kami akan menjelaskan isolasi, identifikasi struktur dan aktivitas sitotoksik triterpenoid damaran dari kulit batang C. macrophyllus.

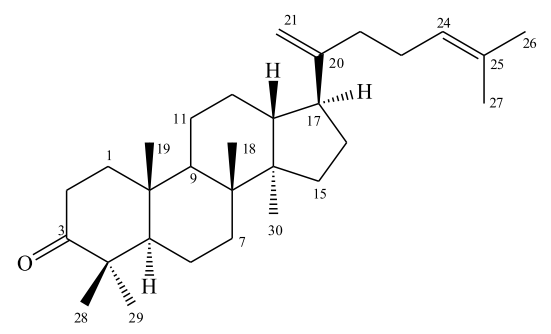

PERCOBAAN
Umum. Titik leleh diukur dengan peralatan titik leleh Fisher-John (tidak terkoreksi). Spektra IR diperoleh dari spektrofotometer FTIR spectrum One Perkin Elmer pada $\mathrm{KBr}$. Spektra $1 \mathrm{H}-$ dan $13 \mathrm{C}-\mathrm{NMR}$ diperoleh dengan spektrometer JEOL JNM ECA-500. Spektra MS diperoleh dengan Mariner Biospectrometry-Finnigan instrument. Pemisahan kromatografi dilakukan pada silika gel G60, silika gel (70230 dan 200-400 mesh, Merck). KLT plat diisi dengan silika gel GF254 (Merck, 0,25 mm) dan deteksi di lakukan dengan penampak noda $10 \% \mathrm{H}_{2} \mathrm{SO}_{4}$ dalam etanol diikuti dengan pemanasan.

Bahan tanaman. Kulit batang C. macrophyllus diperoleh dari Kebun Raya Bogor, Jawa Barat pada bulan September 2011. Tumbuhan ini dideterminasi di Herbarium Bogoriense, Pusat penelitian Biologi, LIPI, Bogor dan contoh specimen (No. Bo-1295450) tersimpan di Herbarium tersebut.

Ekstraksi dan Isolasi. Serbuk kering kulit batang C. macrophyllus $(3,1 \mathrm{Kg})$ diekstraksi berturut-turut dengan $n$-heksan, etil asetat dan metanol pada temperatur kamar. Setelah penguapan pelarut pada tekanan rendah dihasilkan berturut-turut ekstrak nheksan $(38,8 \mathrm{~g})$, etil asetat $(53,5 \mathrm{~g})$ dan metanol $(137,2$ g). Ekstrak n-heksan (38,8 g) dipisahkan dengan kromatografi cair vakum (KCV) dengan eluen n-heksanetil asetat-metanol, yang meningkat kepolarannya sehingga dihasilkan 5 fraksi utama (A-E), digabungkan berdasarkan anilisis KLT. Fraksi C $(17,7 \mathrm{~g})$ dipisahkan lebih lanjut dengan kromatografi kolom pada silika gel (230-400 mesh) dengan eluen n-heksan:kloroform (1:1) sehingga dihasilkan 5 fraksi utama (C1-C5), digabungkan berdasarkan analisis KLT. Fraksi C3 $(6,1 \mathrm{~g})$ dipisahkan lebih lanjut dengan kromatografi kilat pada silika gel (200-400 mesh) dengan campuran eluen nheksan:kloroform (4:1) diperoleh 5 fraksi utama (C3.1C3.5). Pada fraksi C.3.2 dihasilkan endapan dan dimurnikan lebih lanjut dengan kristalisasi dalam metanol dihasilkan senyawa damara-20,24-dien-3-on (18 mg). 
Damara-20,24-dien-3-on (1), diperoleh berupa kristal jarum tak berwarna; titik leleh,141-143 ${ }^{\circ} \mathrm{C}$; IR $(\mathrm{KBr})$ Vmaks1709, 1611, $1015 \mathrm{~cm}^{-1} .{ }^{1} \mathrm{H}$ - dan ${ }^{13} \mathrm{C}-\mathrm{NMR}$ ( $\mathrm{CDCl}_{3}, 500 \mathrm{MHz}$ untuk ${ }^{1} \mathrm{H}$ - dan $125 \mathrm{MHz}$ untuk ${ }^{13} \mathrm{C}-$ NMR): lihat Tabel 1. HR-ESI-TOFMS $(\mathrm{m} / z$ 957,12 $[2 \mathrm{M}+\mathrm{Ag}]+$.

Uji Sitotoksik, ${ }^{17}$ Sel kanker payudara manusia MCF-7 (ATCC, Manassas, VA, USA) dikultur pada medium RPMI-1640 (Sigma, MO, USA), ditambah 10\% serum fetal bovin dan antibiotik $(100 \mathrm{U} / \mathrm{mL}$ penicillin and $100 \mu \mathrm{g} / \mathrm{mL}$ streptomycin). Untuk perlakuan sel, beberapa konsentrasi dari senyawa uji ditambahkan pada medium kultur sel selama 24 jam. Analisis proliferasi sel dilakukan terhadap beberapa konsentrasi senyawa uji melalui uji MTT kalorimetri. Sel $\left(2 \times 10^{4}\right.$ in $50 \mu \mathrm{L} /$ lubang) ditempatkan pada plat 96 lubang. Setelah penambahan sel awal, beberapa konsentrasi dari senyawa uji ditambahkan dan diinkubasi selama 24 jam. $10 \mathrm{~mL}$ dari tetrazolium yang larut dalam air (WST)uji kit ploriferasi cepat (Biovision, CA, USA) ditambahkan pada masing-masing lubang dan diinkubasi selama $37^{\circ} \mathrm{C}$ selama 3 hari. Setelah penambahan $100 \mu \mathrm{L} /$ lubang dari $1 \mathrm{~N} \mathrm{HCl}$, laju proliferasi sel ditentukan dengan pengukuran serapan pada panjang gelombang $450 \mathrm{~nm}$, dengan panjang gelombang referensi $650 \mathrm{~nm}$. Serapan dibaca dengan pembaca plat mikrotiter (Thermo Scientific, MA, USA).

\section{HASIL DAN PEMBAHASAN}

Senyawa 1 diperoleh berupa kristal jarum tak berwarna.Rumus molekul senyawa 1 ditetapkan sebagai $\mathrm{C}_{30} \mathrm{H}_{48} \mathrm{O}$ berdasarkan spektrum massa $(\mathrm{m} / \mathrm{z}$ $957,12[2 \mathrm{M}+\mathrm{Ag}]+$, bersama dengan data NMR (Tabel 1 ), dengan demikian senyawa 1 memiliki 7 derajat ketidakjenuhan. Senyawa 1 transparan di bawah sinar UV pada panjang gelombang 254 dan $367 \mathrm{~nm}$, menunjukkan tidak adanya ikatan rangkap terkonyugasi. Spektrum IR menunjukkan adanya serapan yang berasal dari gugus karbonil (Vmaks 1709 $\mathrm{cm}^{-1}$ ), ikatan rangkap dua terisolasi(maks $1611 \mathrm{~cm}-1$ ) dan eter (vmaks $1015 \mathrm{~cm}^{-1}$ ). Spektrum ${ }^{1} \mathrm{H} \mathrm{NMR}$ menunjukkan adanya sinyal proton dari tujuh metil tersier pada dH 0,88; 0,95; 1,02; 1,05; 1,09; 1,62; dan 1,70 (masing-masing $3 \mathrm{H}$, singlet), satu proton metin $\mathrm{sp} 2$ pada $\mathrm{dH} 5,13(1 \mathrm{H}, \mathrm{m})$ dan dua proton $\mathrm{sp}^{2}$ terminal pada $\delta \mathrm{H}[4,72(1 \mathrm{H}, \mathrm{d}, \mathrm{J}=8,2 \mathrm{~Hz})$ dan 4,75 $(1 \mathrm{H}, \mathrm{d}, \mathrm{J}=8,2$ $\mathrm{Hz})$ ]. Spektrum ${ }^{13} \mathrm{C}$ NMR menunjukkan adanya 30 sinyal karbon yang diperinci dengan percobaan DEPT dan HMQC sebagai satu karbonil pada $\delta C 218,1$; satu sinyal sp2 metin pada dC 124,4 ; satu sinyal sp2 metilen pada dC 107,6; dua sinyal sp ${ }^{2}$ kuarterner pada $\delta C 152,5$ dan 131,4; sepuluh karbon metilen sp3, empat karbon metin sp3, empat karbon $\mathrm{sp}^{3}$ kuarterner, dan tujuh karbon metil tersier. Fungsionalitas ini dihitung sebagai tiga dari tujuh total derajat ketidakjenuhan, empat derajat ketidakjenuhan tersisa sesuai dengan kerangka triterpenoid damaran tetrasiklik.

Untuk menentukan posisi gugus karbonil dan olefinik pada senyawa 1 , percobaan COSY dan HMBC dilakukan dan hasilnya dapat dilihat pada Gambar 1. Pada spektrum HMBC, korelasi yang tampak dari proton metil tersier terhadap karbon tetangganya dapat menjelaskan keberadaan tujuh metil tersier pada
Tabel 1. Data NMR untuk senyawa 1 dalam $\mathrm{CDCl}_{3}$

\begin{tabular}{|c|c|c|}
\hline \multirow[b]{2}{*}{ Posisi C } & \multicolumn{2}{|r|}{1} \\
\hline & $\delta_{\mathrm{C}}$ ppm (Mult.) & $\begin{array}{c}\delta_{\mathrm{H}} \text { ppm (Int.; Mult., } \\
J=\mathrm{Hz})\end{array}$ \\
\hline 1 & 39,9 (d) & $1,47(1 \mathrm{H}, \mathrm{m}) ; 1,96(1 \mathrm{H}, \mathrm{m})$ \\
\hline 2 & $34,1(d)$ & $1,98(1 \mathrm{H}, \mathrm{m}) ; 2,47(1 \mathrm{H}, \mathrm{m})$ \\
\hline 3 & $218,1(\mathrm{~s})$ & - \\
\hline 4 & $47,4(\mathrm{~s})$ & - \\
\hline 5 & 53,4 (d) & $1,38(1 \mathrm{H}, \mathrm{m})$ \\
\hline 6 & $19,7(\mathrm{t})$ & $1,49(1 \mathrm{H}, \mathrm{m}) ; 1,58(1 \mathrm{H}, \mathrm{m})$ \\
\hline 7 & $34,7(t)$ & $1,32(1 \mathrm{H}, \mathrm{m}) ; 1,66(1 \mathrm{H}, \mathrm{m})$ \\
\hline 8 & $40,3(\mathrm{~s})$ & - \\
\hline 9 & $50,3(d)$ & $1,40(1 \mathrm{H}, \mathrm{m})$ \\
\hline 10 & $36,9(\mathrm{~s})$ & - \\
\hline 11 & $21,9(\mathrm{t})$ & $1,26(1 \mathrm{H}, \mathrm{m}) ; 1,55(1 \mathrm{H}, \mathrm{m})$ \\
\hline 12 & $28,9(\mathrm{t})$ & $1,43(1 \mathrm{H}, \mathrm{m}) ; 1,94(1 \mathrm{H}, \mathrm{m})$ \\
\hline 13 & $45,4(d)$ & $1,67(1 \mathrm{H}, \mathrm{m})$ \\
\hline 14 & $49,4(\mathrm{~s})$ & - \\
\hline 15 & $31,3(\mathrm{t})$ & $1,13(1 \mathrm{H}, \mathrm{m}) ; 1,58(1 \mathrm{H}, \mathrm{m})$ \\
\hline 16 & $24,9(\mathrm{t})$ & $1,20(1 \mathrm{H}, \mathrm{m}) ; 1,60(1 \mathrm{H}, \mathrm{m})$ \\
\hline 17 & 47,7 (d) & $2,18(1 \mathrm{H}, \mathrm{m})$ \\
\hline 18 & $15,8(q)$ & $0,88(3 \mathrm{H}, \mathrm{q})$ \\
\hline 19 & $16,1(\mathrm{q})$ & $0,95(3 \mathrm{H}, \mathrm{q})$ \\
\hline 20 & $152,5(\mathrm{~s})$ & - \\
\hline 21 & $107,6(t)$ & $4,72(1 \mathrm{H}, \mathrm{d}, 8,2) ; 4,75(1 \mathrm{H}, \mathrm{d}, 8,2)$ \\
\hline 22 & $34,1(\mathrm{t})$ & $1,97(1 \mathrm{H}, \mathrm{m}) ; 2,02(1 \mathrm{H}, \mathrm{m})$ \\
\hline 23 & $27,1(\mathrm{t})$ & $2,13(1 \mathrm{H}, \mathrm{m}) ; 2,40(1 \mathrm{H}, \mathrm{m})$ \\
\hline 24 & $124,4(d)$ & $5,13(1 \mathrm{H}, \mathrm{m})$ \\
\hline 25 & $131,4(\mathrm{~s})$ & - \\
\hline 26 & $25,7(q)$ & $1,70(3 \mathrm{H}, \mathrm{q})$ \\
\hline 27 & $17,7(q)$ & $1,62(3 \mathrm{H}, \mathrm{q})$ \\
\hline 28 & $21,1(q)$ & $1,05(3 \mathrm{H}, \mathrm{q})$ \\
\hline 29 & $16,7(q)$ & $1,09(3 \mathrm{H}, \mathrm{q})$ \\
\hline 30 & $15,3(\mathrm{q})$ & $1,02(3 \mathrm{H}, \mathrm{q})$ \\
\hline
\end{tabular}

senyawa 1 . Dua proton metilen pada $\delta \mathrm{H} 1,47$ dan 1,98 saling terjodoh satu sama lain dan berkorelasi dengan C-3 ( $\delta C 218,1)$ dan C-4 $(\delta C 47,4)$, sedangkan proton metil pada $\delta \mathrm{H} 1,05$ berkorelasi dengan $\mathrm{C}-3(\delta \mathrm{C} 218,1)$ dan $\mathrm{C}-5(\delta C 53,4)$, menyarankan bahwa gugus karbonil terletak pada C-3. Dua proton olefinik pada $\delta \mathrm{H} 4,72$ dan 4,75 saling terjodoh dua ikatan $\left({ }^{2} J\right)$ dan berkorelasi dengan C-20 ( $\delta C 152,5), C-17(\delta C 47,7)$ dan C-22 ( $\delta C$ $34,1)$, sedangkan proton metin pada $\mathrm{dH} 2,18$ berkorelasi dengan $C-20(\delta C 152,5), C-16(\delta C 24,9)$ dan $\mathrm{C}-22(\delta \mathrm{C} 34,1)$, menyarankan posisi gugus olefinik terminal terletak pada C-20 dan C-21 $(\Delta 20,21)$. Proton olefinik pada $\delta \mathrm{H} 5,13$ berkorelasi dengan $\mathrm{C}-25$ ( $\delta \mathrm{C}$ $131,4)$ dan $C-23(\delta C 27,1)$, sedangkan proton metil pada $\delta \mathrm{H} 1,70$ berkorelasi dengan $\mathrm{C}-25(\delta \mathrm{C} 131,4)$ dan $\mathrm{C}-24$ ( $\delta C$ 124,4), menyarankan posisi ikatan rangkap dua yang lain terletak pada C-24 dan C-25. Perbandingan data NMR senyawa 1 dengan damara-20,24-dien-3on,menunjukkan kesesuaian yang tinggi, dengan demikian senyawa 1 diidentifikasikan sebagai damara20,24-dien-3-on.

Senyawa damara-20,24-dien-3-on menunjukkan aktivitas sitotoksik terhadap sel kanker payudara manusia MCF-7 dengan nilai IC50 $28 \mu \mathrm{M}$.

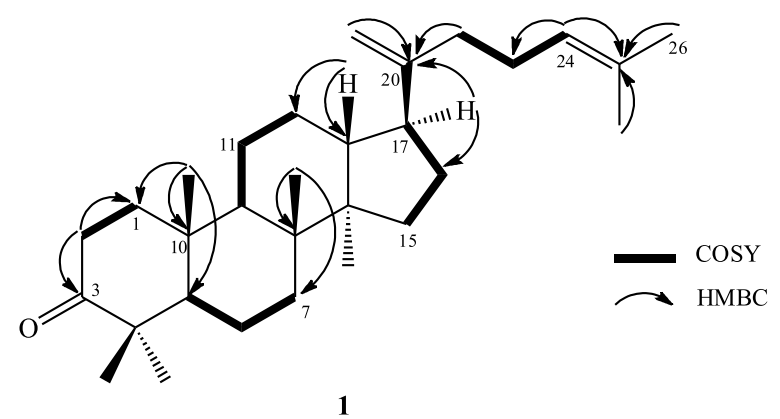




\section{DAFTAR PUSTAKA}

Yang, M. H., Wang, J. S., Luo, J. G., Wang, X. B., Kong, L. Y., "Tetranortriterpenoids from Chisocheton paniculatus" J. Nat. Prod. 2009, 72, 2014-2018.

Hidayat, S. S., Hutapea, J. R., "Indonesian Medicinal Plants", Research and Devolepment Agency, Ministry of Health, Jakarta, Indonesia, 1991.

Heyne, K., "The Useful Indonesian Plants", Research and Development Agency, Ministry of Forestry, Jakarta, Indonesia.1982.

Jain, D. C., and Tripathi, A.K., "Potential of natural products as insect antifeedant". Phytother. Res., 1993, 7, 327-334.

Roy, A., and Sarat, S., "Limonoids: Overview of significant bioactive triterpenes distributed in plants kingdom". Biol. Pharm. Bull., 2006, 29, 191-201.

Siddiqui, B. S., Afshan, F., Ghiasuddin, F. S., Naqvi, S. N. H., Tariq, R. M. "Two insecticidal tetranortriterpenoids from Azadirachta indica". Phytochemistry, 2000, 53, 371-376.

Najmuldeen, I. A., Hadi, A. H. A., Awang, K., Mohamad, K., Ketuly, K. A., Mukhtar, M. R., Chong, S. L., Chan, G., Nafiah, M. A., Weng, N. S., Shirota, O., Hosoya, T., Nugroho, A., Morita, H., "Chisomicines A-C, Limonoids from Chisocheton ceramicus".J. Nat. Prod., 2011, 74, 1313-1317.

Wong, C. P., Shimada, M., Nagakura, Y., Nugroho, A. E., Hirasawa, Y., Kaneda, T., Awang, K., Hadi, A. H. A., Mohamad, K., Shiro, M., Morita, H., "Ceramicines E-I, New limonoids from Chisocheton ceramicus".Chem. Pharm. Bull., 2011, 59(1), 407-411.I

Laphookhieo, S., Maneerat, W., Koysomboon, S., Kiattansuki, R. Chantrapromma, K., Syera, J. K., "A novel limonoid from the seeds of Chisocheton siamensis".Can. J. Chem., 2008, 86, 205208.

Connolly, J. D. Labbe, C., Rycroft, D. S., Taylor, D. A. H. "Tetranortriterpenoids and related compounds. Part 22. New apotirucallol derivatives and tetranortriterpenoids from the wood and seeds of Chisocheton paniculatus (Meliaceae)". J. Chem. Soc. Perkin Trans. I., 1979, 12, 2959-2964.

Gunning, P. J., Jeffts, L. B., Isman, M. B., Towers, G. H. N., "Two limonoids from Chisocheton microcarpus".Phytochemistry, 1994, 36, 1245-1248.

Bordoloi, M., Saikia, B., Mathur, R. K., Goswami, B. N., "A meliacin from Chisocheton panniculatus". Phytochemistry, 1993, 34, 583 584.

Inada, A., Somekawa, M., Murata, H., Nakanishi, T., Tokuda, H., Nishino, H., Iwashima, A., Darnaedi, D., Murata, J., "Phytochemical studies on Meliaceous plants. VIII. Structures and inhibitory effects on epstein-barr virus activation of triterpenoids from leaves of Chisocheton macrophyllus King". Chem. Pharm. Bull., 1993, 41(3), 617-619.

Chan, K. Y., Mohamad, K., Ooi, A. J. A., Imiyabir, Z., Chung, L. Y. "Bioactivity-guided fractionation of the lipoxygenase and cyclooxygenase inhibiting constituents from Chisocheton polyandrus Merr".Fitoterapia, 2012, 83, 961-967.

Stevens, P. F., "Review of Chisocheton (Meliaceae) in Papuasia. Division of Botany, Department of Forest, Lae, Papua New Guinea". Present: The Arnold Arboretum of Harvard University, Cambridge, Massachusetts, 1980, 02138, USA.

Vossen, V. D., and Umali, B. E., "Plant Resources of South East Asia, No. 14, Vegetable oil and fats". Prosea Foundation, Bogor, Indonesia, 2002.

Faried, A., Faried, L. S., Kimura, H., Sohda, M., Nakajima, M., Miyazaki, T., Kato, H., Kanuma, T., Kuwano, H., "Differential sensitivity of paclitaxelinduced apoptosis in human esophageal squamous cell carcinoma cell lines". Cancer Chemother. Pharmacol., 2006, 57(3):301-308.

Chan, K. Y., Mohamad, K., Ooi, A. J. A., Imiyabir, Z., Chung, L. Y., "Bioactivity-guided fractionation of the lipoxygenase and cyclooxygenase inhibiting constituents from Chisocheton polyandrus Merr". Fitoterapia, 2012, 83, 961-967.

Phongmaykin, J., Kumamoto, T., Ishikawa, T., Suttisri, R., Saifah, E., “ A new sesquiterpene and other constituents of Chisocheton penduliflorus". Arch. Pharm. Res., 2008, 31, 21-27.

Revesz, L., Hiestand, P., La Vecchia, L., Naef, R., Naegeli, H. U., Oberer, L., "Isolation and synthesis of a novel immunosuppressive 17asubstituted damarane from the flour of the Palmyrah palm (Borassus flabellifer)". Bioorg. Med. Chem. Lett., 1999, 9, 15211526. 